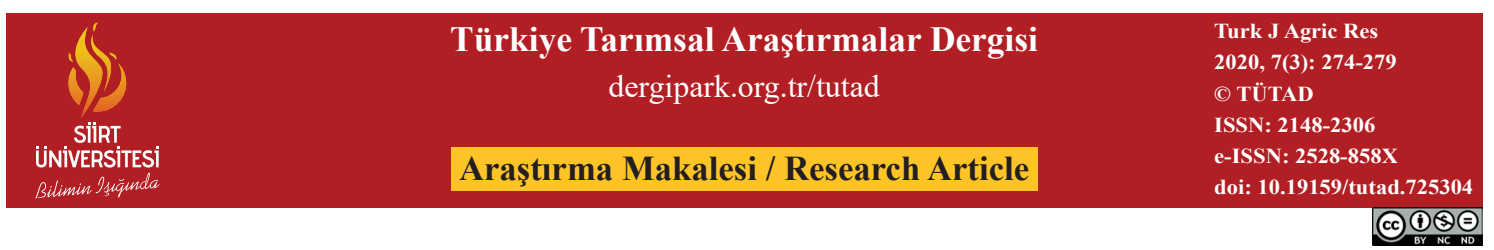

\title{
Bazı Maş Fasulyesi (Vigna radiata Wilczek) Genotiplerinin Meloidogyne incognita Irk 2 ile Reaksiyonu
}

\author{
Fatma Gül GÖZE ÖZDEMİR ${ }^{1 *}$, Ruziye KARAMAN² \\ ${ }^{1}$ Isparta Uygulamalı Bilimler Üniversitesi, Ziraat Fakültesi, Bitki Koruma Bölümü, Isparta, TÜRKIYYE \\ ${ }^{2}$ Isparta Uygulamalı Bilimler Üniversitesi, Ziraat Fakültesi, Tarla Bitkileri Bölümü, Isparta, TÜRKIYYE
}

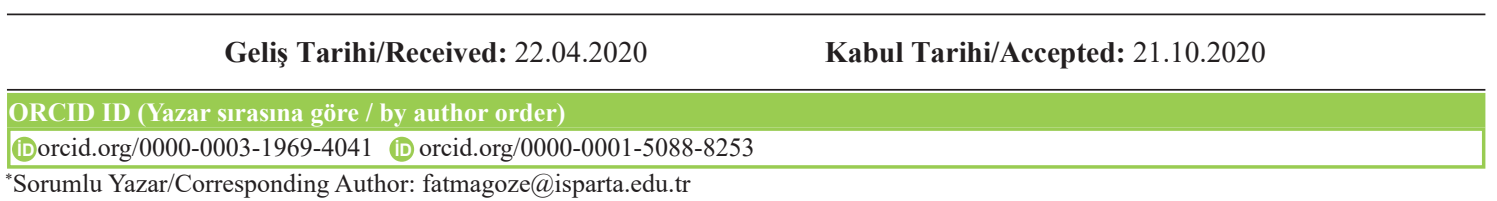

Öz: Bu çalışmada, Türkiye'nin farklı yerlerinden temin edilen maş fasulyesi (Vigna radiata Wilczek) genotiplerinin Meloidogyne incognita urk 2 ile reaksiyonu ve genotiplerin konukçu durumlarının belirlenmesi amaçlanmıştır. Bu amaca yönelik olarak çalışmada, maş fasulyesine ait 14 farklı genotip ve 1 adet tescilli çeşit kullanılmış; değerlendirme işlemi 1-9 kök ur skalası ve yumurta paketi üretim oranı skalası üzerinden yapılmış ve dayanıklılık indeksi hesaplanmıştır. Çalışma sonucunda; $M$. incognita urk 2'ye karşı 1 genotipte yüksek seviyede dayanım, 1 orta seviyede dayanım, 2 orta düzey konukçu, 2 çok hassas, 5 orta hassas ve 4 hassas reaksiyon saptanmıstır. Yüksek seviyede dayanım belirlenen $50 \mathrm{~N} 01$ adlı genotipte gal indeksi 1.4, yumurta paketi üretim oranı 1.8 ve dayanıklılık indeksi 6.4 bulunurken, 30 Ç 01 adlı genotipte gal indeksi 3.4, yumurta paketi üretim oranı 4.4 ve dayanıklılık indeksi 31.4 saptanmıştır. Araştırma sonucuna göre, 30 Ç 01 ve $50 \mathrm{~N} 01$ genotiplerinin M. incognita' ya karşı dayanıklı çeşit geliştirmek için melezleme çalışmalarında ebeveyn olarak kullanılabileceği belirlenmiştir.

Anahtar Kelimeler: Maş fasulyesi, Meloidogyne incognita, dayanıklılık, konukçu reaksiyonu, nematod gal indeksi

\section{The Reaction of Some Mung Bean (Vigna radiata Wilczek) Genotypes with Meloidogyne incognita Race 2}

\begin{abstract}
In this study, it was aimed to determine the reactions and host states of different mung bean (Vigna radiata Wilczek) genotypes, collected from different regions of Turkey, with Meloidogyne incognita race 2. For this purpose, 14 different mung bean genotypes and one registered variety were used in the study. The evaluation process was made according to 1-9 root gall scale and the egg package production rate scale, and resistance index was calculated. As a result of the study, a high level of resistance in 1 genotype, 1 moderate resistance, 2 intermediate hosts, 2 very susceptible, 5 medium susceptible, and 4 susceptible reactions were detected against $M$. incognita race 2 . In the genotype named $50 \mathrm{~N} 01$ with high resistance, the gall index was 1.4 , the egg mass production rate was 1.8 , and the resistance index was 6.4 , while the gall index was 3.4, the egg mass production rate was 4.4 and the resistance index was 31.4 in the genotype named 30 Ç 01 . According to the study results, the genotypes $30 \mathrm{CC} 01$ and $50 \mathrm{~N} 01$ could be used as a parent in hybridization studies to develop resistant varieties against $M$. incognita.
\end{abstract}

Keywords: Mung bean, Meloidogyne incognita, resistance, host reaction, nematode gall index

\section{Giriş}

Üç tarafı denizlerle kaplı olan Türkiye'nin pek çok ekolojik farklılıkları bulunması sebebiyle dünyada tüketilen yemeklik tane baklagil türlerinden maş fasulyesi (Vigna radiata Wilczek), lima fasulyesi ve acı bakla gibi bitkilerin rahatlıkla tarımı yapılabilmektedir (Bozoğlu ve Topal, 2005). 
Nitekim tohum toplama amaciyla yapılan bir survey çalışmasında, Türkiye'de yaklaşık 200 yıldır maş fasulyesi tarımının yapıldığ olarak Akdeniz ve Güneydoğu Anadolu Bölgesi'nde yaygın olarak yetiştirildiği rapor edilmiştir (Karaman, 2019).. Maş fasulyesinin Bradyrhizobium japonicum bakterisi ile simbiyotik ilişki içerisinde olması ve toprağa $58-109 \mathrm{~kg} \mathrm{ha}^{-1}$ arasında değişen miktarda azot fikse edebilmesi önemini arttırmaktadır (Singh ve Singh, 2011; Karaman, 2019).

Dünyada maş fasulyesi ile yapılan çalışmaların çok az sayıda olduğu görülmüş ve hastalık ve zararlıları ile yapılan geniş kapsamlı bir çalışmanın bulunmadığı belirlenmiştir. Aynı şekilde, Türkiye'de taze ve kuru fasulye çeşitlerinde nematodlarla ilgili çalışmalar bulunmasına rağmen, maş fasulyesinde bir çalışmaya rastlanılmamıştır. Praveen (2018), maş fasulyesinin en önemli hastalığının sarı mozaik virüsü olduğunu bildirmiş ve bu hastalığın \% 100 verim kaybına neden olabildiğini ifade etmiştir. Bitki paraziti nematodlar maş fasulyesi bitki büyüme ve gelişmesinde ağır hasara neden olabilmektedir (Tiyagi ve Alam, 1995). Sasser ve Freckman (1987), maş fasulyesinde bitki paraziti nematodlardan kaynaklanan ürün kaybını \% 10.9 olarak bildirmektedirler.

Geniş konukçu dizisine sahip kök-ur nematodları (Meloidogyne spp.)'nın köklerde beslenmesi sonucu oluşan urlar, bitkinin topraktan besin ve su alımina engel olmakta; bunun sonucunda bitkide sararma, solma, meyvelerde küçülme, büyümede bodurluk görülmektedir. Ayrıca beslenme sırasında bitki köklerinde açtıkları yaralar, bakteri ve fungus gibi sekonder patojenlere de giriş kapısı oluşturmaktadır (Wang ve ark., 2013; Gürkan ve ark., 2019). Domates ve fasulyede kök-ur nematodu enfeksiyonunun yapraklardaki fotosentez oranlarını önemli derecede azalttığı bulunmuştur (Loveys ve Bird, 1973; Melakeberhan ve ark., 1984). Türkiye'de bitkilerdeki nematodlar üzerine yapılan çalışmalarda Meloidogyne incognita, M. javanica, M. arenaria, M. hapla, M. chitwoodi, M. artiellia, M. acrita, M. luci, M. exiqua ve $M$. thamesi türleri tespit edilmiştir (Kepenekçi ve ark., 2002; Cetintas ve Cakmak, 2016; Uysal ve ark., 2017; Aydınlı, 2018). Dünyada fasulye alanlarında en yaygın $M$. incognita (Kofoid ve White) Chitwood türü bulunmakta ve fasulye türlerinde \% 90 oranında kalite ve verim kaybına neden olmaktadır (Shree ve Schwartz, 2011). Gürkan ve ark. (2019), Gaziantep ve Osmaniye illerinde fasulye örneklerinde $M$. incognita'y1 tespit etmişlerdir. Uysal ve ark. (2017), fasulyeden aldıkları bir örnekte Isparta ilinde $M$. incognita'y1 tespit ederken, Burdur iline ait bir örnekte $M$. javanica belirlemişlerdir.

Bitki paraziti nematodların mücadelesinde genel olarak dayanıklı çeşit, ürün rotasyonu ve nematisitler kullanılmaktadır (Göze Özdemir ve Uysal, 2018). Kullanılan sentetik nematisitlerin yüksek toksisiteleri sebebiyle çevre, doğal yaşam ve insan sağlığına olumsuz etkileri olduğu belirlenmiş ve birçoğunun toprak fümigantı olarak kullanımı yasaklanmıştır (Abawi ve Widmer, 2000; Sorribas ve ark., 2005). Ürün rotasyonu ise konukçu dizisi geniş olan bitki paraziti nematod türlerinde tercih edilememektedir. Bitki dayanıklılığ1, konukçusuyla özel bir etkileşim gösteren Meloidogyne cinsi için nematod yönetiminde en çok arzu edilen taktik olarak kabul edilmiştir (Roberts, 2002). Bitkilerdeki nematod dayanımını değerlendirmek için en iyi kriter konukçudaki nematod üreme oranlarını bulmaktır (Salgado ve ark., 2005). Bu nedenle geniş spektrumlu konukçu reaksiyonu çalışmaları ıslah programları için büyük önem taşımaktadır (Boerma ve Hussey, 1992).

$\mathrm{Bu}$ çalışmanın amacı, Türkiye'den toplanan maş fasulyesi ( $V$. radiata Wilczek) genotiplerinde $M$. incognita 1rk 2 kök-ur nematodu patojenitesi ve dayanıklı/hassas konukçu reaksiyonlarının belirlenmesidir.

\section{Materyal ve Yöntem}

\subsection{Tohum materyali}

Araştırmada, maş fasulyesi ( $V$. radiata Wilczek) tohum materyalini; Türkiye'nin farklı bölgelerinden (Antalya, Gaziantep, Hakkâri, Mersin, Konya, Kahramanmaraş, Nevşehir, Tokat, Karaman ve Şırnak) toplanan genotipler ve Avustralya'dan temin edilen Jade-AU çeşidi oluşturmuştur (Tablo 1).

Tablo 1. Çalışmada kullanılan materyallerin genotip adı ve toplandıkları yerler

\begin{tabular}{lll}
\hline No & Genotip adı & Toplandı̆̆ı yer \\
\hline 1 & Jade -UA & Avustralya Maş Fasulyesi Birliği \\
2 & 07 A 03 & Antalya- Alanya \\
3 & 07 G 03 & Antalya- Gazipaşa \\
4 & 07 G 09 & Antalya- Gazipaşa \\
5 & 27 N 01 & Gaziantep-Nizip \\
6 & 27 S 01 & Gaziantep-Şahinbey \\
7 & 30 Ç 01 & Hakkâri- Çukurca \\
8 & 33 A 01 & Mersin-Anamur \\
9 & 33 M 01 & Mersin-Mut \\
10 & 42 M 01 & Konya-Meram \\
11 & 46 G 01 & Kahramanmaraş-Göksu \\
12 & 50 N 01 & Nevşehir \\
13 & 60 M 01 & Tokat \\
14 & 70 E 03 & Karaman-Ermenek \\
15 & 73 A & Şırnak \\
\hline
\end{tabular}




\subsection{Nematod materyali}

Kök-ur nematodu materyalini, iklim odası koşullarında $\left(24 \pm 1{ }^{\circ} \mathrm{C}, \% 60 \pm 5\right.$ nem koşullarında) kitle üretimi devam eden, morfolojik ve moleküler olarak tanılanmış M. incognita ırk 2 G7 (Devran ve Sögüt, 2011) izolatının II. dönem larvaları oluşturmaktadır. Kök-ur nematodları obligat oldukları için canlı bitki üzerinde kitle üretimleri devam ettirilmekte ve 2-3 ayda bir yenilenmektedir. Kitle üretimleri Tueza F1 domates çeşidi ile yürütülmüştür.

\section{3. İkinci dönem larva eldesi}

Domateste kitle üretimi devam ettirilen $M$. incognita 1rk 2 G7 izolatının yumurta paketleri urlu köklerinden binoküler mikroskop altında pens ve bistüri yardımıyla çıkarılmıştır. Elde edilen yumurta paketleri distile su içeren petri içerisinde elekler içerisine alınarak $28{ }^{\circ} \mathrm{C}$ 'de üç gün inkübe edilmiştir. $\mathrm{Bu}$ şekilde yumurta paketlerinden II. dönem larvalarının çıkışları sağlanmıştır. Elekten mezura alınan suyun çökelme işlemi tamamlandıktan sonra 1şık mikroskobu altında II. dönem larvalarının sayımları yapılarak efendorf tüpleri içerisine alınmıştır.

\subsection{Maş fasulyesi genotiplerinde nematod gelişimi ve konukçu reaksiyonu}

Çalışma, 2018-2019 yıllarında Isparta Uygulamalı Bilimler Üniversitesi Ziraat Fakültesi iklim odasinda $\quad\left(24 \pm 1 \quad{ }^{\circ} \mathrm{C}, \quad \% \quad 60 \pm 5 \quad\right.$ nem koşullarında) yürütülmüştür. Çalışmada steril edilmiş \% 70 kum, \% 20 silt, \% 10 kil içeren toprak karışımı bulunan 250 cc'lik plastik saksılar kullanılmıştır. Deneme tesadüf parselleri deneme desenine göre her genotip için 5 tekerrürlü olarak kurulmuştur. Her saksıya 1 tohum atılmış ve 15 gün sonra nematod inokulasyonu gerçekleştirilmiştir. Nematod inokulasyonu her saksıya 1000 M. incognita II. dönem larva gelecek şekilde yapılmış ve üzerine biraz toprak eklendikten sonra saksılar sulanmıştır.

Çalışma 9 hafta sonra sonlandırılmıştır. Kökler topraktan ayrıldıktan sonra tazikli su altında zarar verilmeden yıkanmış ve 1şık mikroskobu altında ur ve yumurta paketi sayımı yapılmıştır. Nematod değerlendirme işlemi 1-9 kök ur skalası $(1=$ ur yok, $2=\% 5$ kök urlanması, $3=\%$ 6-10 kök urlanmas1, 4=\% 11-18 kök urlanmas1, 5= \% 19-25 kök urlanması, $6=\%$ 26-50 kök urlanması, $7=\%$ 51-65 kök urlanması, 8= \% 66-75 kök urlanmas1, $9=\%$ 76-100 kök urlanmas1) ve yumurta paketi üretim oranı skalası (1= yumurta paketi yok, $2=1$ yada 2 yumurta paketi, 3= 3-6 yumurta paketi, $4=7-10$ yumurta paketi, $5=11-20$ yumurta paketi, $6=21-30$ yumurta paketi, $7=31-60$ yumurta paketi, $8=61-100$ yumurta paketi, 9=100'den fazla yumurta paketi) üzerinden yapılmış ve dayanıklılık indeksi hesaplanmıştır (Mullin ve ark., 1991; Bozbuga ve ark., 2015). Dayanıklılık indeksi [Dİ= 2 (dirençli/bağışı), Dİ= 3-8 (yüksek seviyede dayanıklı), Dİ= 9-18 (dayanıkl1), Dİ= 19-32 (orta dayanıkl1), Dİ= 33-50 (orta düzey konukçu), Dİ= 51-72 (orta hassas), $\mathrm{DI}=73-98$ (hassas), Dİ= 99-162 (çok hassas)] ise Eşitlik 1 yardımıyla hesaplanmış ve konukçu reaksiyonu belirlenmiştir.

$$
\mathrm{DI}=\mathrm{US}^{2}+\mathrm{YPS}^{2}
$$

Eşitlikte US, ur skalasını; YPS ise yumurta paketi skalasını ifade etmektedir.

\section{5. İstatistiksel analiz}

Elde edilen veriler SPSS (version 20) istatistik paket programı kullanılarak standart varyans analizi tekniğinde (ANOVA) analiz edilmiş ve ortalamalar arasındaki farklılıklar Tukey karşıllaştırma testine göre belirlenmiştir (Tukey, 1949).

\section{Bulgular ve Tartışma}

Çalışmada kullanılan genotiplerin $M$. incognita ırk 2'ye karşı gösterdiği konukçu reaksiyonunda farklılıklar saptanmıştır. Ayrıca M. incognita 1rk 2'nin tüm genotiplerde geliştiği ve maş fasulyesinde önemli zarar oluşturabileceği ortaya konmuştur. Çalışmada kullanılan 15 maş fasulyesi genotipinden sadece $50 \mathrm{~N} 01$ ve 30 Ç 01 adlı genotiplerde dayanım belirlenmiş, diğer genotiplerde $M$. incognita 1rk 2'nin geliştiği ve ürediği tespit edilmiştir. Çalışmada kullanılan $50 \mathrm{~N}$ 01 adlı genotipte kök ur skalası 1.4, yumurta paketi skalası 1.8 olarak belirlenirken; dayanıklılık indeksi 6.4 olarak bulunmuş olup, $M$. incognita $\mathrm{rk}$ 2'ye karşı yüksek seviyede dayanım gösterdiği saptanmıştır. Meloidogyne incognita ırk 2'ye karşı orta dayanıklı reaksiyon tespit edilen 30 Ç 01 adlı genotipte ise ur skalas1 3.4, yumurta paketi skalas1 4.4 olarak belirlenirken, dayanıklılık indeksi 31.4 olarak saptanmıştır. Çalışmada, 50 N 01 ve 30 Ç 01 maş fasulyesi genotiplerinde ur ve yumurta paketi skalası ile dayanıklılık indeksi parametreleri yönünden her iki genotip arasındaki farklılık istatistiki olarak anlamlı bulunmuştur $(p<0.05)$. Araştırmada, 07 G 09 ve 70 E 03 adlı genotipler ise, dayanıklılık indeksine göre değerlendirildiğinde $M$. incognita'ya orta düzey konukçu olarak belirlenmiştir. Çalışmada kullanılan 15 maş fasulyesi genotipinin $M$. incognita'ya karşı konukçu reaksiyonu değerlendirildiğinde; 2 tanesi çok hassas, 5 tanesi orta hassas ve 4 tanesi hassas reaksiyon göstermiştir. Orta hassas konukçu reaksiyonu veren genotiplerde ur skala değeri 4.4-5.6 arasında 
değişiklik göstermektedir. Çok hassas konukçu reaksiyonu tespit edilen $27 \mathrm{~N} 01$ ve 07 G 03 adlı genotiplerde ise, ur skalası sirasiyla 7.4 ve 7.2 olarak tespit edilmiştir (Tablo 2).

Çalışmada yumurta paketi skalası ur skalası değerlerinden daha yüksek belirlenmiştir. $\mathrm{Bu}$ durum 1 gal üzerinde birden fazla yumurta paketi bulunmasindan kaynaklanmaktadir. Yumurta paketi skalası 5-7 arasında olan 8 genotip bulunurken, 7 ve üzerinde olan 4 genotip saptanmıştır. Yumurta paketi skalası 5'in altında olan 3 genotip belirlenmiş ve en düşük 1.8 ile $50 \mathrm{~N}$ 01 adlı genotipte tespit edilmiştir. Çalışmada, 30 Ç 01 ve 70 E 03 adl1 genotiplerde yumurta paketi skalası sırasıyla 4.4 ve 4.6 olarak saptanmış ve genotipler arasındaki fark istatistiki olarak önemsiz bulunmuştur $\quad(\mathrm{p}>0.05)$. Ancak konukçu reaksiyonuna bakıldığında 70 E 03 adlı genotip orta düzey konukçu olarak bulunurken, 30 Ç 01 adlı genotip orta dayanıklı saptanmıştır (Tablo 2).

Tablo 2. Maş fasulyesi genotiplerinin Meloidogyne incognita ile reaksiyonu*

\begin{tabular}{|c|c|c|c|c|}
\hline Genotipler & $\begin{array}{l}\text { Gal indeksi } \\
(1-9 / \text { kök })\end{array}$ & $\begin{array}{c}\text { Yumurta paketi oran } 1 \\
(1-9 / \text { kök })\end{array}$ & $\begin{array}{l}\text { Dayanıkl1l1k } \\
\text { indeksi }\end{array}$ & Konukçu reaksiyonu \\
\hline $50 \mathrm{~N} 01$ & $1.4 \pm 0.2 \mathrm{~g}$ & $1.8 \pm 0.4 \mathrm{~h}$ & $6.4 \pm 2.1 \mathrm{e}$ & Yüksek seviyede dayanıklı \\
\hline 07 G 09 & $4.0 \pm 0.0 \mathrm{ef}$ & $5.2 \pm 0.2 \mathrm{efg}$ & $43.2 \pm 0.2 \mathrm{~d}$ & Orta düzey konukçu \\
\hline 70 Е 03 & $3.6 \pm 0.2 \mathrm{ef}$ & $4.6 \pm 0.2 \mathrm{fg}$ & $34.6 \pm 3.9 \mathrm{~d}$ & Orta düzey konukçu \\
\hline 30 Ç 01 & $3.4 \pm 0.2 \mathrm{f}$ & $4.4 \pm 0.2 \mathrm{~g}$ & $31.4 \pm 3.9 \mathrm{de}$ & Orta dayanıklı \\
\hline 33 M 01 & $5.6 \pm 0.2 \mathrm{bc}$ & $6.4 \pm 0.2 \mathrm{~b}-\mathrm{e}$ & $72.8 \pm 5.3 \mathrm{bc}$ & Hassas \\
\hline 27 S 01 & $6.0 \pm 0.0 \mathrm{~b}$ & $7.0 \pm 0.0 \mathrm{abc}$ & $85.0 \pm 0.0 \mathrm{~b}$ & Hassas \\
\hline 07 A 03 & $5.4 \pm 0.2 \mathrm{bcd}$ & $6.6 \pm 0.4 \mathrm{a}-\mathrm{d}$ & $73.6 \pm 8.0 \mathrm{bc}$ & Hassas \\
\hline 42 M 01 & $5.6 \pm 0.2 b c$ & $7.2 \pm 0.3 \mathrm{ab}$ & $84.0 \pm 7.5 b$ & Hassas \\
\hline 33 А 01 & $4.4 \pm 0.2$ def & $5.6 \pm 0.2 \mathrm{~d}-\mathrm{g}$ & $51.2 \pm 4.4 \mathrm{~cd}$ & Orta hassas \\
\hline Jade-AU & $5.2 \pm 0.2 \mathrm{bcd}$ & $6.4 \pm 0.2 \mathrm{~b}$-e & $68.4 \pm 4.8 \mathrm{bc}$ & Orta hassas \\
\hline 60 M 01 & $5.4 \pm 0.2 \mathrm{bcd}$ & $6.4 \pm 0.2 \mathrm{~b}-\mathrm{e}$ & $70.6 \pm 5.8 \mathrm{bc}$ & Orta hassas \\
\hline $46 \mathrm{G} 01$ & $4.6 \pm 0.2 \mathrm{cde}$ & $5.8 \pm 0.2 \mathrm{c}-\mathrm{f}$ & $55.2 \pm 3.9 \mathrm{~cd}$ & Orta hassas \\
\hline $73 \mathrm{~A}$ & $4.4 \pm 0.2 \mathrm{def}$ & $5.6 \pm 0.2 \mathrm{~d}-\mathrm{g}$ & $51.2 \pm 4.4 \mathrm{~cd}$ & Orta hassas \\
\hline 07 G 03 & $7.2 \pm 0.2 \mathrm{a}$ & $7.8 \pm 0.2 \mathrm{a}$ & $113.0 \pm 4.7 \mathrm{a}$ & Çok hassas \\
\hline $27 \mathrm{~N} 01$ & $7.4 \pm 0.2 \mathrm{a}$ & $7.6 \pm 0.2 \mathrm{ab}$ & $113.0 \pm 6.7 \mathrm{a}$ & Çok hassas \\
\hline
\end{tabular}

*: Aynı sütunda aynı harfle gösterilen ortalamalar arasındaki fark istatistiki olarak anlamlı değildir $(\mathrm{p}<0.05)$

$\mathrm{Bu}$ çalışma maş fasulyesi genotiplerinde $M$. incognita 1rk 2'ye karşı dayanıklılıkta genetik çeşitliliğin olduğunu göstermiştir. Bu durum, maş fasulyesi genotiplerinin sahip olduğu genetik özelliklerinden kaynaklanmaktadır. Ahmed ve ark. (2009), maş fasulyesinde [V. radiata (L.) Wilczek cv. MN95] kök-ur nematodu inokulasyonundan 15,30 ve 45 gün sonra meydana gelen fizyolojik ve biyokimyasal değişiklikleri inceledikleri çalışmada bitkilerde klorofil ve karotenoid içeriğinin azaldığını tespit etmişlerdir. Ayrıca nematod inokulasyonundan 30 gün sonra bitkideki toplam fenol ve protein içeriği ile amilaz aktivitesinin azaldığ ${ }_{1}$ saptanmış ve bitkilerin nematodun olumsuz etkilerine dayanacak biyokimyasal stratejiler uygulayarak yanıt verdiğini belirtmişlerdir. Wesemael ve Moens (2011), fasulye çeşitlerinde Meloidogyne türlerinin farklı reaksiyonlar verdiğini bulmuşlardır. Bozbuga ve ark. (2015), Türkiye de iklim odası koşullarında yaptıkları çalışmada, 87 Phaseoulus vulgaris L. genotipinin $M$. incognita'ya karş1 konukçu hassasiyetini araştırmışlar ve 13 tanesinin kök-ur nematoduna dayanıklı çeşit ıslahında potansiyel teşkil ettiğini bildirmişlerdir. Chakraborty ve ark. (2016), 68 maş fasulyesi genotipinden 4 tanesinin $M$. incognita'ya karşı orta seviyede dayanım gösterdiğini bildirmektedirler. Devi ve ark. (2014), 28 maş fasulyesi genotipinden 24 tanesinin $M$. incognita 1rk 2'ye karşı hassas konukçu reaksiyonu gösterdiğini ve ur skala değerinin 3-5 arasında değiştiğini tespit ederken, 4 tanesinin çok hassas reaksiyon verdiğini bulmuşlardır. Gupta ve ark. (1986), 219 maş fasulyesi varyete ve hattında $M$. javanica türünün reaksiyonuna bakmışlar ve 7 tanesi çok hassas, 198 tanesi hassas ve 15 tanesinde orta düzeyde dayanıklılık bildirmişlerdir.

\section{Sonuçlar}

Kök-ur nematodları ile mücadelede kimyasal nematisitlere gelen kısıtlamalar, dayanıklı çeşit kullanımını arttırmıştır. Dayanıklı çeşit geliştirilmesi için çok sayıda genotipin nematodlarla konukçu reaksiyonlarının belirlenmesi önemlidir. $\mathrm{Bu}$ etkin genotiplerin belirlenmesi yeni dayanıkl1 hatlar oluşturulabilmesine imkân sağlamaktadır. Bu çalışmada $50 \mathrm{~N} 01$ ve 30 Ç 01 genotiplerinin maş fasulyesi 1slah çalışmalarında kullanılabileceği belirlendiği gibi $M$. incognita ile bulaşık alanlarda bu 2 tohum kaynağının kullanılması önerilebilinir. 


\section{Kaynaklar}

Abawi, G.S., Widmer, T.L., 2000. Impact of soil health management practices on soilborne pathogens, nematodes and root diseases of vegetable crops. Applied Soil Ecology, 15(1): 37-47.

Ahmed, N., Abbasi, M.W., Shaukat, S., Zakî, M.J., 2009. Physiological changes in leaves of mungbean plants infected with Meloidogyne javanica. Phytopathology Mediterrean, 48(2): 262-268.

Aydınl, G., 2018. Detection of the root-knot nematode Meloidogyne luci (Tylenchida: Meloidogynidae) in vegetable fields of Samsun Province, Turkey. Türkiye Entomoloji Dergisi, 42(3): 229-237.

Boerma, H.R., Hussey, R.S., 1992. Breeding plants for resistance to nematodes. Journal of Nematology, 24(2): 242-252

Bozbuga, R., Dasgan, H.Y., Akhoundnejad, Y., Imren, M., Toktay, H., Bortecine Kasapoglu, E., 2015. Identification of common bean (Phaseolus vulgaris) genotypes having resistance against root knot nematode Meloidogyne incognita. Legume Research, 38(5): 669-674.

Bozoğlu, H., Topal, N., 2005. Ülkemiz için yeni yemeklik tane baklagil türleri. 6. Tarla Bitkileri Kongresi, Bildiriler Kitabı, 5-9 Eylül, Antalya, Türkiye, s. 557-562.

Chakraborty, G., Mondal (Ghosh), S., Samanta, P. , Karmakar, P., Roy, D., 2016. Screening of some urdbean and mungbean germplasm for their reactions to root-knot nematode, Meloidogyne incognita (Kofoid and White) Chitwood. National Symposium on Impact of Climate Change, Biodiversity and Good Plant Protection Practices for Crop Productivity, 22-23 December, Kalyani, West Bengal, India, pp. 9.

Cetintas, R., Cakmak, B., 2016. Meloidogyne species infesting tomatoes, cucumbers and eggplants grown in Kahramanmaraş Province, Turkey. Türkiye Entomoloji Dergisi, 40: 355-364.

Devi, G., Choudhary, B.N., Bhagawati, B., 2014. Screening of mungbean variety/germplasm against root-knot nematode (Meloidogyne incognita) race-2. Indian Journal of Nematology, 44: 251-252.

Devran, Z., Söğüt, M.A., 2011. Characterizing races of Meloidogyne incognita, $M$. javanica and $M$. arenaria in the West Mediterranean region of Turkey. Crop Protection, 30(4): 451-455.

Gupta, D.C., Paruthi, I.J., Verma, K.K., 1986. Reaction of mungbean germplasms and its pathogenicity against Meloidogyne javanica. Indian Journal of Nematology, 16(2): 194-196.

Gürkan, B., Çetintaş, R., Gürkan, T., 2019. Gaziantep ve Osmaniye sebze alanlarında bulunan kök-ur nematodu türleri (Meloidogyne spp.)'nin teşhisi ile bazı nematod popülasyon irklarının belirlenmesi. Kahramanmaraş Sütçü İmam Üniversitesi Tarım ve Doğa Dergisi, 22(Ek Say1 1): 113-124.

Göze Özdemir, F.G., Uysal, G., 2018. Nematoda dayanıklılık sağlayan genlerin etkinliği ve sürekliliğinde ürün yönetim stratejileri. Türk Bilimsel Derlemeler Dergisi, 11(1):40-47.

Karaman, R., 2019. Maş fasulyesi (Vigna radiata Wilczek) genotiplerinin/yerel populasyonlarının isparta koşullarında fenolojik, morfolojik, agronomik ve bazı teknolojik özellikler yönünden karakterizasyonu. Doktora tezi, Süleyman Demirel Üniversitesi, Fen Bilimleri Enstitüsü, Isparta.

Kepenekçi, İ., Öztürk, G., Evlice, E., 2002. Ülkemiz örtü alt1 sebze üretiminde sorun olan yeni bir kök-ur nematodu türü (Meloidogyne exigua Goeldi, 1887) ve diğer kök-ur nematodu türleri. IV. Sebze Tarımı Sетроzуити, Bildiriler kitab1, 17-20 Eylül, Bursa, s. 55.

Loveys, R.R., Bird, A.F., 1973. The influence of nematodes on photosynthesis in tomato plants. Physiological Plant Pathology, 3: 525-529.

Melakeberhan, H., Webster, J.M., Brooke, R.C., 1984. Improved techniques for measuring the $\mathrm{CO}_{2}$ exchange rate of Meloidogyne nematode bean plants. Nematologica, 30: 213-221.

Mullin, B.A., Abawi, G.S., Pastor-Corrales, M.A., Kornegay, J.L., 1991. Reactions of selected bean pure lines and accessions to Meloidogyne species. Plant Disease, 75: 1212-1216.

Praveen, K., 2018. Integrated Management of Yellow Mosaic Virus Disease of Mung Bean. (https://scholar.google.com.tr/scholar?hl=tr\&as_sdt= $0 \% 2$ C $5 \& q=$ Praveen + Kumar+2018.+INTEGRATED +MANAGEMENT+OF+YELLOW+MOSAIC+VIR US+DISEASE+OF+MUNG+BEAN\&btnG $=$ ), (Erişim tarihi: 12. 06.2019).

Roberts, P.A., 2002. Concepts and consequences of resistance. In: J.L. Starr, R. Cook, J. Bridge (Eds.), Plant Resistance to Parasitic Nematodes, Wallingford, CAB International, pp. 23-41.

Salgado, S.M.L., Resende, M.L.V., Campos, V.P., 2005. Reprodução de Meloidogyne exigua em cultivares de cafeeiros resistentes e suscetíveis. Fitopatologia Brasileira, 30: 413-415.

Sasser, J.N., Freckman, D.W., 1987. A world perspective on nematology: the role of the society. In: J.A. Veech and D.W. Dickson (Eds.), Vistas on Nematology, E.O. Painter Printing Co., DeLeon Springs, FL, USA. pp. 7-14.

Shree, P.S., Schwartz, H.F., 2011. Breeding common bean for resistance to insect pests and nematodes: A review. Canadian Journal of Plant Sciences, 91(2): $1-12$.

Singh, D.P., Singh, B.B., 2011. Breeding for tolerance to abiotic stresses in mungbean. Journal of Food Legumes, 24(2): 83-90.

Sorribas, F.J., Ornat, C., Verdejo-Lucas, S., Galeano, M., Valero, J., 2005. Effectiveness and profitability of the $M i$ resistant tomatoes to control root-knot nematodes. European Journal of Plant Pathology, 111(1): 29-38.

Tiyagi, S.A., Alam, M.M., 1995. Efficacy of oil-seed cakes against plant-parasitic nematodes and soil- 
inhabiting fungi on mungbean and chickpea. Bioresource Technology, 51(2): 233-239.

Tukey, J.W., 1949. Comparing individual means in the analyses of variance. Biometrics, 5: 99- 114.

Uysal, G., Söğüt, M.A., Elekçioğlu, İ.H., 2017. Identification and distribution of root-knot nematode species (Meloidogyne spp.) in vegetable growing areas of Lakes Region in Turkey. Türkiye Entomoloji Dergisi, 41(1): 105-122.
Wang, Y., Yang, W., Zhang, W., Han, Q., Feng, M., Shen, H., 2013. Mapping of a heat-stable gene for resistance to southern root-knot nematode in Solanum lycopersicum. Plant Molecular Biology Reporter, 31(2): 352-362.

Wesemael, W.M.L., Moens, M., 2011. Screening of common bean (Phaseolus vulgaris) for resistance against temperate root-knot nematodes (Meloidogyne spp.). Pest Managament Science, 68(5): 702-708. 